\title{
Autograft, Allograft and Xenograft Options in the Treatment of Neglected Achilles Tendon Ruptures: A Historical Review with Illustration of Surgical Repair
}

\author{
by Jason R. Grove, DPM ${ }^{1}$, Mark A. Hardy, DPM, FACFAS ${ }^{2} \square$
}

The Foot \& Ankle Journal 1 (5): 1

Achilles tendon ruptures are injuries that are becoming more common as the participation of recreational activities continue to increase. Fortunately, most acute ruptures are identified and treated within the first month of the injury, whether by immobilization or by primary surgical repair. Ruptures are sometimes missed by physicians or ignored by patients and the consequences of the so-called neglected Achilles rupture can be devastating. Surgical repair of neglected Achilles ruptures is less controversial than that of acute ruptures; however, selection of the most appropriate procedure often proves difficult. There have been a number of surgical approaches described to treat the neglected rupture. We present a review of the surgical approaches described in the literature as well as an illustration of our preferred methods.

Key words: Neglected Achilles tendon rupture, Surgical Achilles tendon repair reproduction in any medium, provided the original work is properly cited. @The Foot \& Ankle Journal (www.faoj.org)

\begin{abstract}
Achilles tendon ruptures were first described in 1575 by Ambrose Paré. ${ }^{1,2}$ Historically, Achilles tendon ruptures were considered rare with an incidence of less than $0.2 \% .^{3-6}$ Over the past decade the rate of ruptures has increased. ${ }^{7-9}$ The Achilles accounted for $40 \%$ of operated tendon ruptures in one study. ${ }^{10}$ Today, the Achilles tendon is the most common tendon ruptured in the lower extremity. ${ }^{4}$ This recent increase in Achilles tendon ruptures is believed to be a consequence of increased participation in recreational acivities. ${ }^{9,11-14}$
\end{abstract}

\footnotetext{
Address correspondence to: Mark A. Hardy, DPM, FACFAS Kaiser Permanente Foundation Department of Podiatric Surgery 12301 Snow Road Parma, OH 44130

Email: markhardy@sbcglobal.net
}

${ }^{1}$ Senior Resident, Kaiser Permanente/Cleveland Clinic Foundation Residency Program, Cleveland, Ohio.

${ }^{2}$ Director, Cleveland Clinic/Kaiser Permanente. Foot \& Ankle Residency Program. Director, Foot and Ankle Trauma Service. Kaiser Permanente - Ohio Region
Inglis and Sculco noted that $75 \%$ of the patients in their study related that the injury occurred during a recreational activity. ${ }^{15}$ Endurance sports such as running and jogging can lead to chronic overuse and subsequent rupture of the tendon. ${ }^{16,17}$

Common symptoms include the feeling of being kicked from behind, ${ }^{8}$ difficulty walking, weakened plantarflexion power, ${ }^{18}$ swelling, and bruising about the ankle. On examination, there may be a palpable gap, ${ }^{8,19,20}$ diminished plantarflexion strength, or a positive Thompson test. ${ }^{21} \mathrm{Ma}$ and Griffith stated that a palpable gap at the rupture site and diminished plantar flexion strength are pathognomonic of an Achilles tendon rupture. ${ }^{22}$ Ecchymosis, edema, and pain on palpation may be present on exam. 
In some patients, the symptoms may diminish quickly, or are minimal enough that they do not seek immediate treatment. ${ }^{23}$ In Christensen's analysis of 57 patients who suffered Achilles tendon ruptures, 19 were said to be painless. ${ }^{24}$ Another concern is a missed diagnosis in the acute setting. It has been noted that up to $20 \%$ of Achilles ruptures are missed on initial exam. ${ }^{25}$ The sequelae of disrupted Achilles tendon function is loss of ankle stability, calcaneal limp, and abnormal gait. ${ }^{26,27}$

There is still confusion in the literature at regarding the point at which an acute rupture is considered neglected. Bosworth noted contraction of the triceps surae complex occurs within 3-4 days after the rupture. ${ }^{28}$ Four weeks is the most often cited interval describing a neglected Achilles tendon rupture. ${ }^{9,29-31}$ The neglected Achilles rupture consists of a large gap with secondary contracture of the gastro-soleus complex $^{32}$ resulting in over-lengthening and weakness. Healing may not be directly related to return of functional activity. ${ }^{29}$ Neglected ruptures often pose a more difficult task to the treating physician than do acute ruptures. ${ }^{32-34}$ Barnes and Hardy showed that untreated Achilles ruptures heal with scar tissue filling the resultant gap. ${ }^{35}$ The main factor in the success or failure of healing is the functional length of the muscle-tendon unit. Interposed scarring can impair the functional end result by weakening the plantar flexion power and cause instability about the ankle. ${ }^{23,27,29}$ The ability to produce tension in an over-lengthened musculotendinous unit is poor. ${ }^{29,35}$

Surgical treatment of acute ruptures is still under debate. ${ }^{12,20,36-38}$ Surgical treatment of neglected Achilles ruptures has been well documented to be more effective than conservative treatment in providing the patient better function. ${ }^{17,29,31,33,34,39,40-}$ ${ }_{47}$ Cetti, et al, found $75 \%$ of those treated with surgery had acceptable results, whereas only $56 \%$ of those treated with casting had return of normal function. ${ }^{3}$ Nonetheless, surgical treatment of Achilles ruptures pose many challenges to the surgeon. ${ }^{15,33,47}$
There are complications that can occur with these surgeries, in particular, a high rate of wound complications such as dehiscence and infection. ${ }^{15,16,49}$

Christensen in 1931 was the first to report surgical treatment of neglected Achilles tendon ruptures. ${ }^{50}$ Since that time, a number of reconstruction techniques have been described to treat neglected Achilles ruptures. Unfortunately, none of these techniques have shown evidence of superiority through comparative studies. ${ }^{7,8,51}$ The surgical techniques have been categorized into two main groups: autologous and synthetic or allograft repair. The autologous techniques include augmentation with free fascia or tendon graft, fascia advancement or turn-down flaps, and local tendon transfers. ${ }^{52}$

\section{Surgical Techniques}

\section{Autografts}

The free fascia lata graft was first described by Bugg and Boyd in 1968. ${ }^{44}$ Maffulli described the use of a free gracilis graft for augmentation. ${ }^{53}$ The fascia advancement technique was popularized by Abraham and Pankvich in 1974 with the V-Y plasty. $^{44}$ The gastrocnemius-soleus turn-down flap was described by Arner and Lindholm in 1959., 2,5,54 Disadvantages of using free grafts include the technical difficulty of some repairs as well as some requiring a separate incision.

Local tendon transfers have become more popular for repair of neglected Achilles rupture. The most commonly used tendons are the peroneus brevis, flexor hallucis longus (FHL), and flexor digitorum longus (FDL) tendons. ${ }^{29}$ The peroneus brevis tendon transfer was first described by White and Kraynick. ${ }^{55}$ Teuffer studied 30 patients with peroneus brevis transfer for neglected Achilles ruptures and at a mean follow up of 5 years, 28 of the 30 patients had excellent results, however he did not distinguish between early and late repairs. ${ }^{56}$ 
Although no evidence suggests abnormal gait after a peroneal brevis transfer, it may be disconcerting since it provides lateral ankle stability and eversion motion. The peroneus brevis is responsible for $28 \%$ of the eversion capacity of the hindfoot. ${ }^{57}$

Mann et al described using the FDL tendon transfer with a turn-down flap and had excellent or good results in 6 out of 7 patients studied. ${ }^{38}$

Hansen described the FHL tendon transfer. ${ }^{45}$ Hansen, and more recently Den Hartog ${ }^{58}$ harvested the tendon through the posterior incision, whereas Wapner ${ }^{32,47}$ described the use of a second incision medially to allow for increased tendon length for transfer. A cadaveric study by Tashjian found that the average length of FHL tendon through a single incision was $5.16 \mathrm{~cm}$ compared to $8.09 \mathrm{~cm}$ when a double incision approach was used..$^{59}$ The $5.16 \mathrm{~cm}$ tendon length was found to be more than adequate for transfer and solid fixation into the calcaneus. The technique described by Wapner involves passing the tendon through a transverse tunnel in the calcaneus and weaving the tendon into the Achilles. Pearsall et al described the use of interference screw fixation for FHL transfer which allows the tendon to be fixated directly into the calcaneus requiring less tendon length. ${ }^{60}$

There are a number of advantages to using the FHL tendon transfer. The FHL is stronger than the peroneus brevis ${ }^{8}$ and Leppilahti ${ }^{9}$ stated that the FHL tendon is twice as strong as FDL. The FHL tendon also maintains normal muscular balance that may be sacrificed with other transfers. Another advantage is the location of the muscle belly in relation to the Achilles tendon. It extends distally into the relatively avascular area of the Achilles tendon, offering a rich supply of blood. ${ }^{14,45,47,61-63}$ As with any tendon transfer, subsequent weakness is a concern. Hansen noted that most patients over 30 years old did not have altered function after the loss of FHL strength. ${ }^{45}$

Coull, et $\mathrm{al}^{64}{ }^{64}$ discovered residual weakness of FHL function, but found no mechanical differences in forefoot loading patterns between the operated foot and the normal, non-operative foot.

\section{Synthetic Materials}

Synthetic materials include Dacron vascular grafts, ${ }^{65}$ carbon fiber composites, ${ }^{66}$ polyglycol threads, ${ }^{67}$ or Marlex mesh. ${ }^{68}$ Early studies showed success with these products. Unfortunately, they do not function as biologic grafts and are incapable of remodeling. ${ }^{40,69,70}$ Furthermore, they may be biologically intolerant and prone to failure as a result of premature loading. ${ }^{40,44,71}$ Amis, et al, observed a significant foreign body response with carbon fiber composites. ${ }^{72}$

\section{Allografts}

Tendon allografts have become popular for ligament and tendon repair in orthopedic and podiatric surgery. In orthopedic surgery, this is particularly true for knee and shoulder reconstruction. In a 5 year follow up comparing autograft and Achilles tendon allograft for anterior cruciate ligament repair, Poehling, et al, found that functional outcomes were similar with fewer activity limitations in the allograft group compared to autograft group. ${ }^{73}$ Nellas in 1996 , Yuen in 2000, and more recently Lepow, et al, in 2006 have described the use of Achilles allograft for treatment of neglected Achilles ruptures with favorable outcomes. ${ }^{746}$ Lepow utilized the allograft alone to repair a $10 \mathrm{~cm}$ gap and at one year follow up the patient was back to pre-injury activity level. ${ }^{76}$ The mechanical strength of rehydrated freeze-dried allografts were found to be similar to autografts in an animal study. ${ }^{77}$ Most studies have now shown that the incorporation and remodeling phases of allografts are longer compared to autografts. ${ }^{77}$ Unfortunately, the use of allografts can carry a small risk of disease transmission, especially HIV and hepatitis C. The most recently published report of the American Association of Tissue Banks states that more than 2 million musculoskeletal allografts have been distributed during the past 5 years with no documented incident of a viral disease transmission caused by an allograft. ${ }^{77}$ 


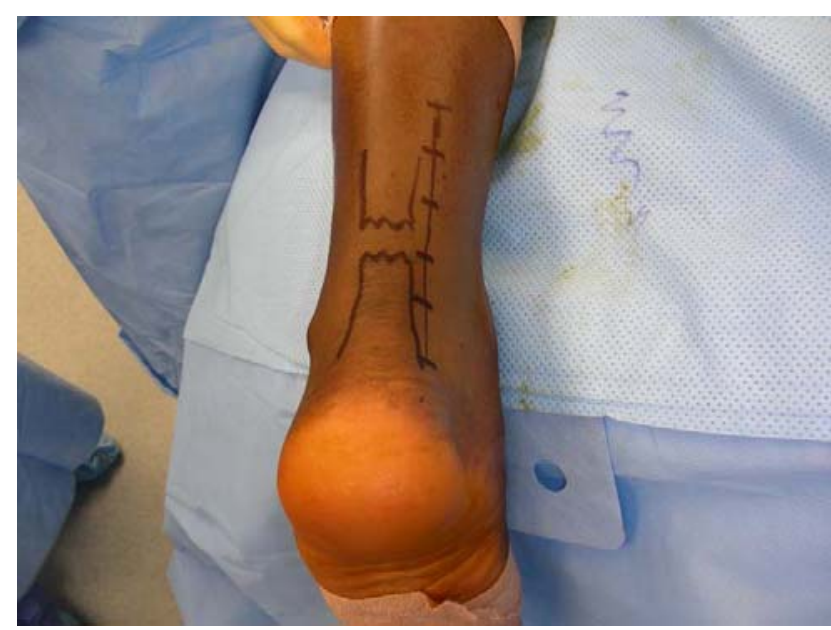

Figure 1 A linear incision is made just medial to the Achilles tendon. This incision allows for adequate exposure while decreasing rate of adhesion formation. The offset incision of the skin and underlying paratenon allows the presence of 2 barriers to the outside environment.

\section{Xenograft}

The OrthADAPT ${ }^{\mathrm{TM}}$ Bioimplant by Pegasus Biologics, Inc. is a xenograft tissue scaffold derived from equine pericardium. It provides an acellular highly organized collagen scaffold allowing for ingrowth and remodeling of normal tendon or ligamentous tissue. It functions to provide augmentation to healing and is not a substitute for tendon. The implant is less bulky than other grafts, with a thickness of $0.5 \mathrm{~mm}$. Because the graft is not of human origin, the usual risk of viral infection as seen in allografts is insignificant. The graft has a shelf-life of two years. It can easily be folded, cut to size, and fenestrated to cover an area of $9 \mathrm{~cm} \times 9 \mathrm{~cm}$. Its use in Achilles tendon ruptures can be useful not only to act as a tendon scaffold, but also to act as a barrier to the underlying tendon in cases when the paratenon is absent or adhered to the skin and must be sacrificed. A major disadvantage to its use is that it adds an avascular substance to an already poorly perfused area..$^{30,78}$

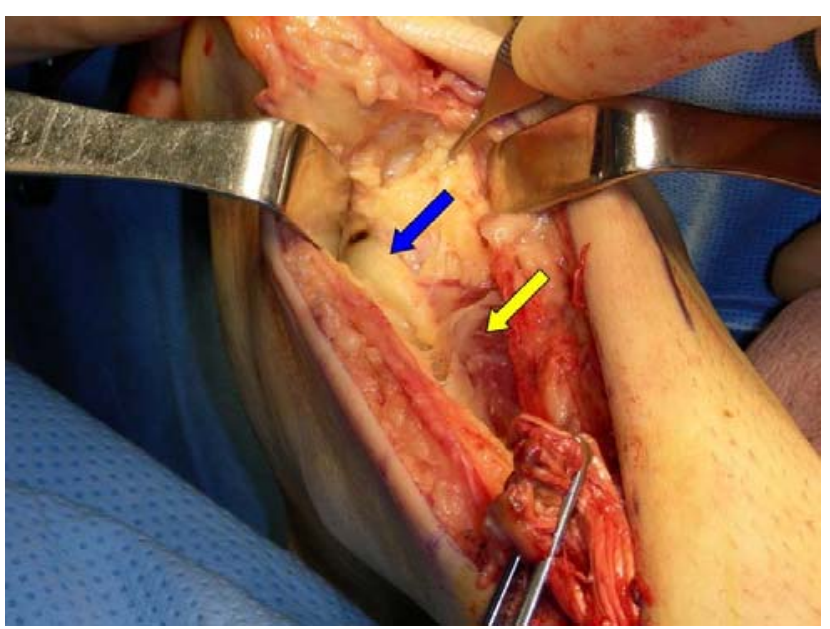

Figure 2 Dissection deep and just medial to the Achilles tendon allows exposure of the flexor hallucis longus tendon. The neurovascular structures lie just deep and medial to the tendon, necessitating the use of blunt dissection in this area. The blue arrow is pointing to the $\mathrm{FHL}$ tendon and the yellow arrow to the FHL muscle belly.

\section{Operative Techniques}

The procedure is performed with the patient prone. General anesthesia is used and a thigh tourniquet used for hemostasis. A ten-centimeter linear posterior skin incision is made just medial to the Achilles tendon. (Fig. 1)

This technique is utilized to offset the incisions of the skin and paratenon to decrease risk of adhesion formation postoperatively. The paratenon is then incised; however it is often noted to be adhered to the underlying postrupture, tissue fibrosis and this portion is usually sacrificed. Upon reflection of the paratenon at the rupture site, an area of fibrotic tissue is often interposed between the ruptured ends of the Achilles tendon. This is completely resected until normal tendon is noted at the distal and proximal ends.

\section{FHL Tendon Transfer}

First the fascia overlying the FHL muscle belly is incised to allow increased perfusion to the remaining Achilles tendon. The FHL tendon is then harvested as described by Hansen. ${ }^{45}$ (Fig. 2) 


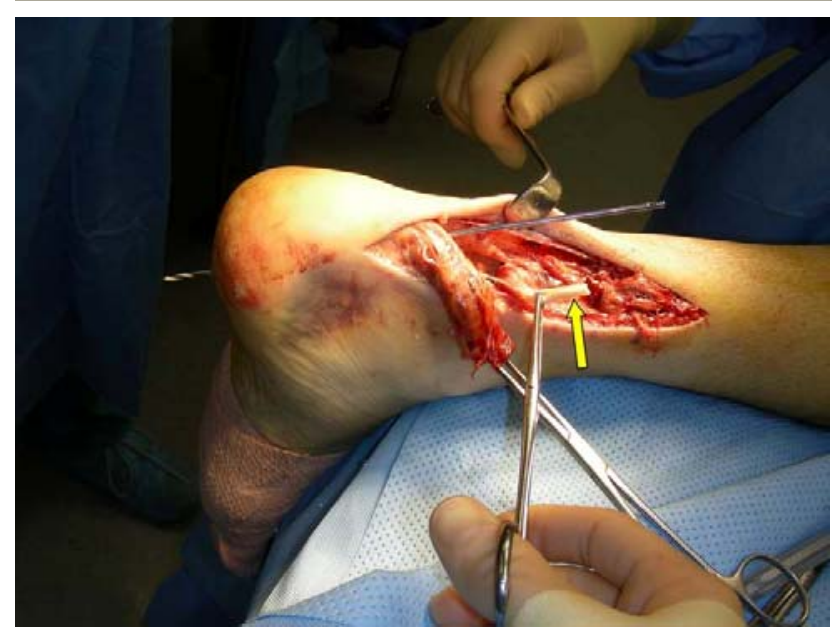

Figure 3 The drill is driven from the superior calcaneal tuber through the plantar cortex. Note the free FHL tendon, highlighted by the yellow arrow, which is ready for transfer.

The tendon of the FHL is freed as distal as possible through the posterior incision. With care taken to protect the adjacent neurovascular structures, the tendon is cut and harvested. For fixation of the transferred tendon, we utilize the Bio-Tenodesis ${ }^{\text {TM }}$ screw. (Arthrex, Naples, FL). The first step is to insert the drill guide. It is inserted from the superior calcaneal tuber through the plantar cortex in a posterior to anterior orientation. The angle of the drill must be such that the drill passes the plantar calcaneal cortex distal to the plantar calcaneal tubercles. (Fig. 3)

After the FHL tendon width is measured, the reamer is then placed over the guide drill and inserted to a depth of the length of the screw. (Figs. 4,5)

Only the superior calcaneal cortex is reamed. This creates the open tunnel and the calcaneus is now ready for insertion of screw and tendon. First, the distal end of the free FHL tendon is secured with the modified Krackow stitch utilizing 2-0 Fiberwire $^{\mathrm{TM}}$. A tendon passer is then inserted from the plantar heel superiorly through the drilled hole. The suture is harvested and the passer is pulled plantarly. This results in the Fiberwire $^{\mathrm{TM}}$ being passed through the plantar heel. (Fig. 6)

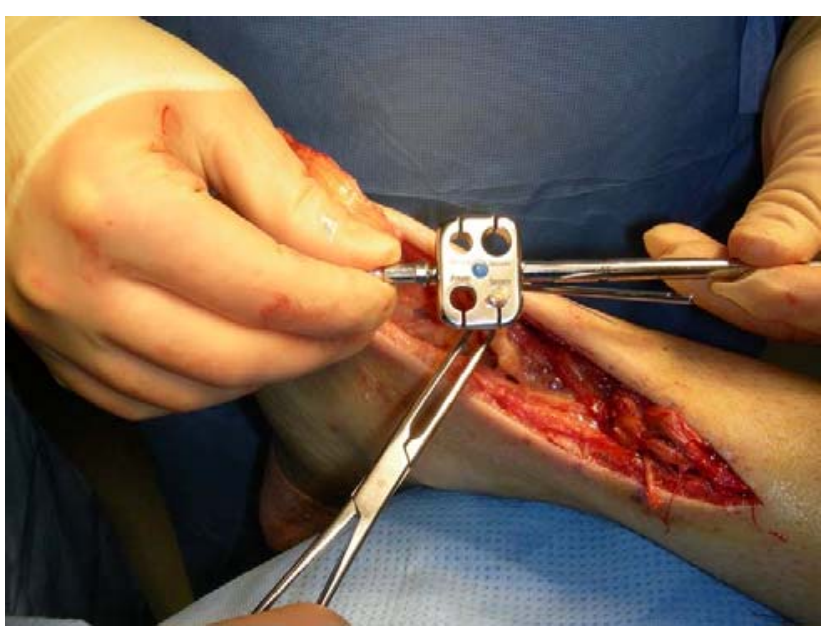

Figure 4 The width of the tendon is measured to determine proper screw and tunnel diameter.

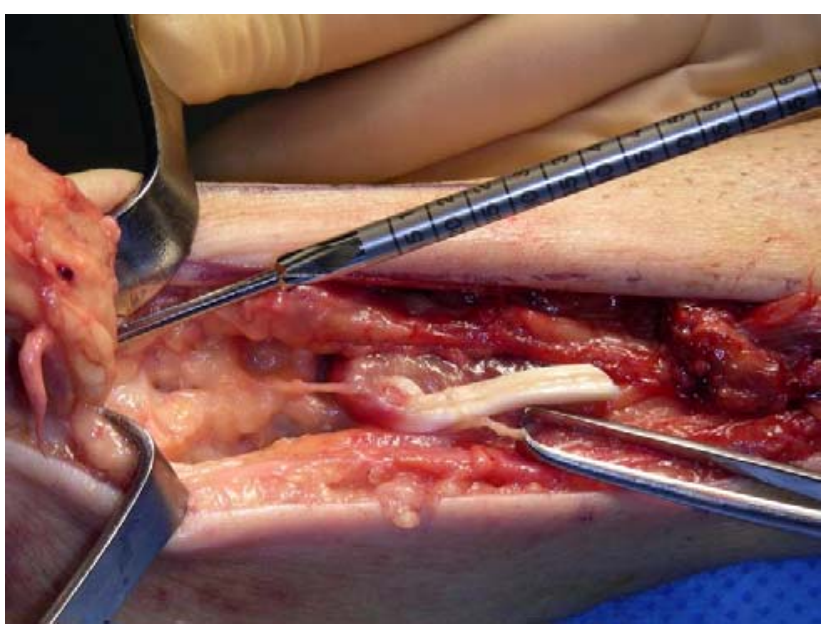

Figure 5 Insertion of the reamer over the guide drill. Only the near cortex is drilled creating the "open" tunnel for interference screw placement. The far (plantar) cortex is often spared during reaming as this helps prevent formation of painful bone callus or creation of a stress fracture.

The last step is to secure the tendon with the screw utilizing the interference technique as described by Pearsall et al. First the Fiberwire ${ }^{\mathrm{TM}}$ exiting the plantar heel is pulled with the foot slightly plantarflexed. Care must be taken to ensure that the FHL tendon freely enters the open tunnel. 


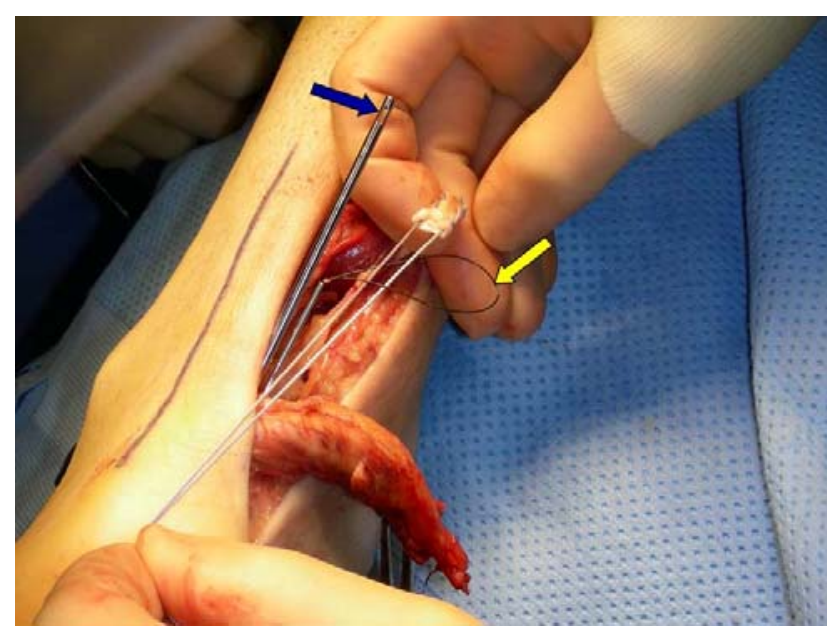

Figure 6 The free FHL tendon is secured with 2-0 Fiberwire $^{T M}$ and then harvested and passed through the tunnel and the suture is pulled out the plantar aspect of the heel. This may be performed with a tendon passer (yellow arrow) or looped through the slot in the drill (blue arrow).

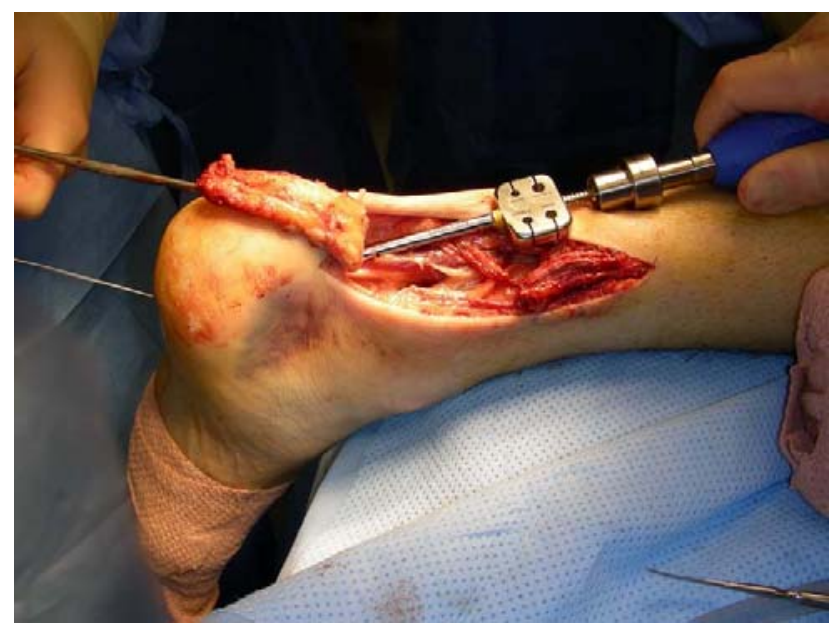

Figure 7 Insertion of interference screw: Notice that there is firm tension on the suture coming out the plantar heel. This will allow proper tension on the suture coming out the plantar heel. This will allow proper tension on the FHL tendon as the screw is inserted. The foot is kept in slight plantarflexion during this maneuver.

While maintaining tension on the Fiberwire ${ }^{\mathrm{TM}}$ with the foot in a slightly plantarflexed position, the FHL tendon is then secured into the superior calcaneus with the Bio-Tenodesis ${ }^{\text {TM }}$ screw. (Fig. 7) The screw must be inserted completely into the calcaneus. The remaining Achilles tendon is then attached to the FHL tendon with 2-0 Fiberwire ${ }^{\mathrm{TM}}$, once again maintaining physiologic tension.

(C) The Foot \& Ankle Journal, 2008

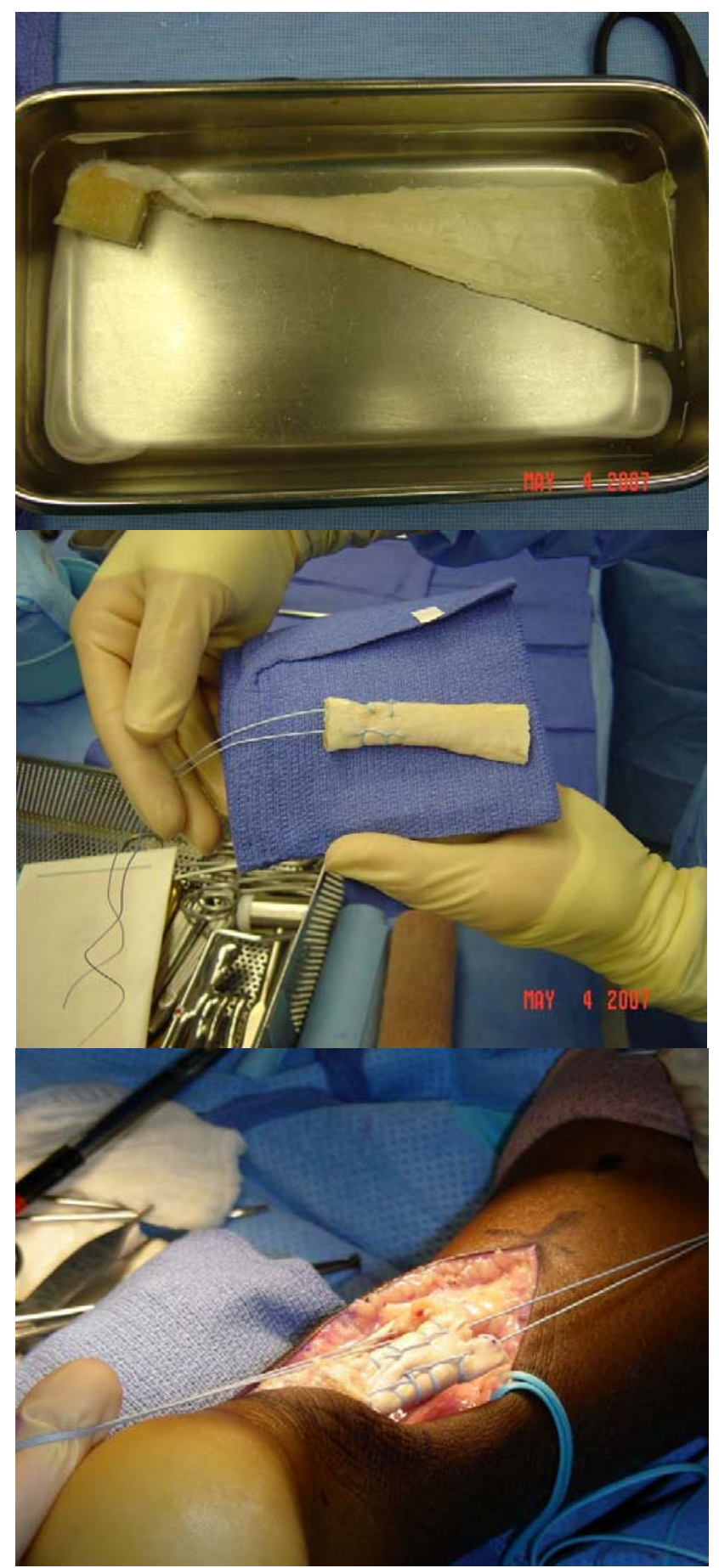

Figures 8,9,10 The cadaveric Achilles tendon allograft: The rehydration process should be performed for at least 30 minutes prior to use. (Fig. 8) The graft is cut to the proper length required to fill the gap and is then prepared for insertion with \#2 Fiberwire ${ }^{\mathrm{TM}}$. (Fig. 9) Insertion of the graft: The suture ends are then tied with the foot slightly in plantarflexion for physiologic tension. (Fig. 10) 


\section{Allograft Achilles Tendon}

The freeze-dried graft (Fig. 8) is allowed to warm and rehydrate in normal sterile saline for at least 30 minutes prior to implantation. The graft is then cut to the length needed to fill the gap left after debridement of scar tissue. \#2 Fiberwire ${ }^{\mathrm{TM}}$ is utilized for its maximal strength to make a running Krackow stitch. (Fig. 9) The graft is then inserted and the free suture ends are tied with the foot in slight plantarflexion. (Fig. 10)

\section{Xenograft}

For further augmentation and due to inadequate paratenon coverage, the OrthADAPT ${ }^{\mathrm{TM}}$ (Pegasus Biologics, Inc, Irvine, CA) (Fig. 11) may be utilized. It is cut to size and wrapped circumferentially around the repair; alternatively, strips of graft may be sutured along the repair. The graft was secured to the Achilles tendon with 2-0 Fiberwire $^{\mathrm{TM}}$. (Fig. 12)

\section{Postoperative Course}

After wound closure, the patient is placed into non-weightbearing posterior splint with the ankle plantarflexed to gravity equinus. The patient is typically kept non-weightbearing for four to six weeks followed by four weeks in walking cast with gradual increase in weightbearing and propulsion. After suture removal (typically at 2 weeks) the patient is then instructed to begin gently range-of-motion exercises at the ankle joint to begin applying mild tension on the healing Achilles tendon, transferred tendon, or graft.

\section{Conclusion}

Neglected Achilles tendon ruptures have become a more common condition than in past decades and represent a difficult challenge for even the most experienced surgeon. Contrary to acute Achilles tendon ruptures, the evidence undoubtedly supports surgical treatment. However, the surgeon has the task of repairing a residual gap, restoring function, and preventing the many complications that commonly occur with Achilles tendon surgeries.

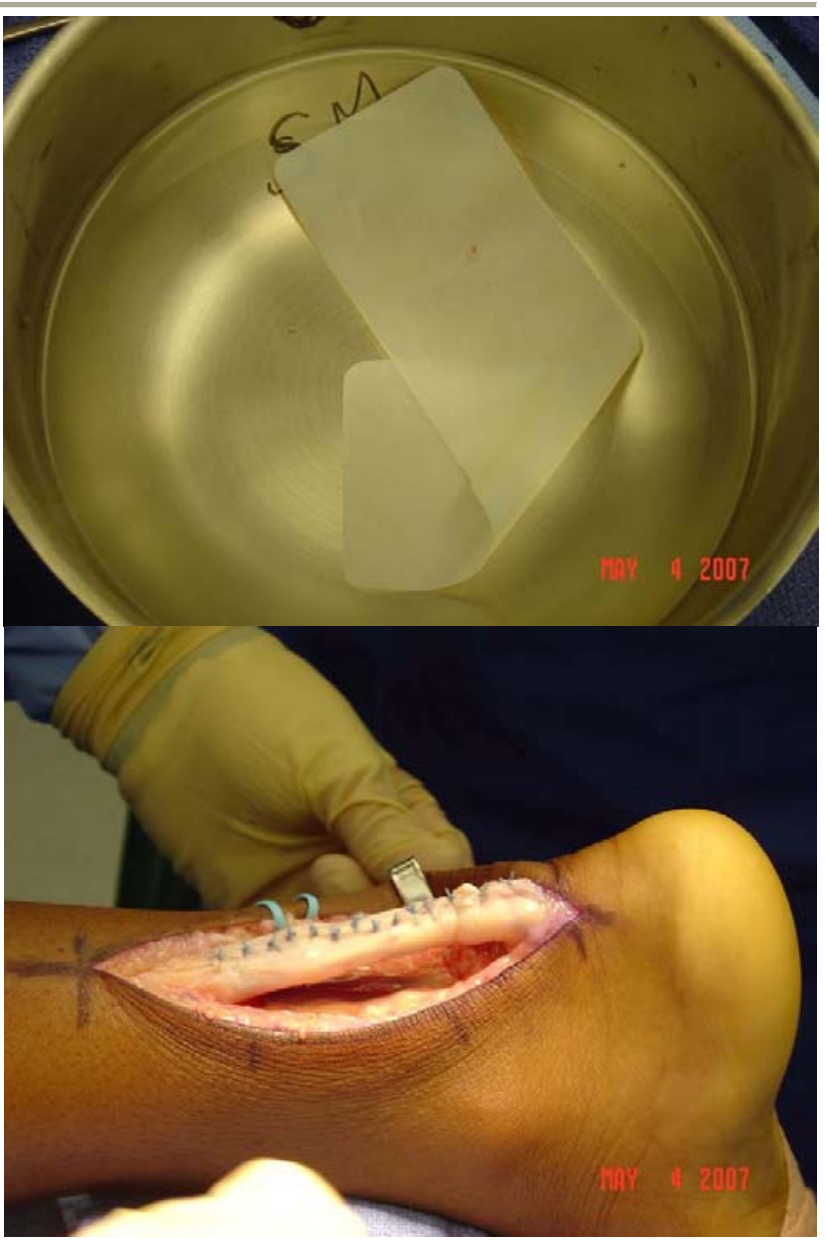

Figures 11,12 OthADAPT ${ }^{\mathrm{TM}}$ graft prior to trimming and application to the Achilles repair. (Fig. 11) The OrthADAPT ${ }^{\mathrm{TM}}$ has been secured with $\# 2$ Fiberwire $^{\mathrm{TM}}$ and acts as a sheath over the repair. (Fig. 12)

Furthermore, a number of surgical and grafting techniques have been described, none of which has become the gold standard. We believe there are distinct advantages of the FHL tendon transfer compared to the alternative techniques. These advantages include 1) tendon harvesting through a single posterior incision , 2) the FHL provides plantarflexory power greater than that of the FDL, 3) it offers a rich vascular supply form its muscle belly, 4) it is less technically demanding than other procedures, 5) and has no significant deleterious effect on the normal biomechanics of the foot. 
In cases that have severe gaps and may require something more substantial than a tendon transfer, we believe the Achilles tendon allograft is a viable option either by itself or with FHL tendon transfer. It has similar strength to autografts and obviates the need for a donor site. It can, however, carry the risk of infectious transmission and takes longer to incorporate than autografts.

Lastly, we also believe the OrthADAPT ${ }^{\mathrm{TM}}$ xenograft allows for an acellular matrix that is useful in reinforcing the FHL or allograft augmentation. We have found that many of the neglected Achilles tendon ruptures have absent or diseased paratenon at the site of injury. Therefore, after the repair, the OrthADAPT ${ }^{\mathrm{TM}}$ provides not only a matrix for the augmented repair to incorporate into, but also a temporary barrier, preventing adhesions postoperatively. We believe these techniques are an effective and practical method for surgical repair of neglected Achilles tendon ruptures.

\section{References}

1. Shalabi A: Magnetic Resonance Imaging in Chronic Achilles Tendinopathy. Acta Radiologica. Suppl 432:1-45, 2004.

2. Arner O, Lindholm A: Subcutaneous Rupture of the Achilles tendon. A study of 92 cases. Acta Chir Scand 239:7-51, 1959.

3. Cetti R, Christensen SE, Ejsted R, et al: Operative versus non-operative treatment of Achilles tendon rupture. A prospective randomized study and review of the literature. Am J Sports Med 21(6):791-799, 1993.

4. Habusta SF: Bilateral simultaneous rupture of the Achilles tendon. A rare traumatic injury. Clin Orthop Relat Res 320:231-234, 1995.

5. Nillius SA, Nilsson BE, Westlin NE: The incidence of Achilles tendon rupture. Acta Orthop Scand 47(1):118-121, 1976.

6. Nistor L: Conservative treatment of fresh subcutaneous rupture of the Achilles tendon. Acta Orthop Scand 47(4):459-462, 1976.

7. Maffulli N, Waterston SW, Squair J, et al: Changing incidence of Achilles tendon rupture in Scotland: a 15-year study. Clin J Sport Med 9:157-160, 1999.

8. Pintore E, Barra V, Pintore R, Maffulli N: Peroneus Brevis tendon transfer in neglected tears of the Achilles tendon. Journal of Trauma, injury, and critical care 50(1):7178, 2001.
9. Leppilahti J, Orava S: Total Achilles Tendon Rupture: A review. Sports Med 25(2):79-100, 1998.

10. Jozsa L, Kvist M, Balint BJ, et al: The role of recreational sport activity in Achilles tendon rupture: a clinical, pathoanatomical, and sociological study of 292 cases. Am J Sports Med 17:338-43, 1989.

11. Shields CL, Jr, Kerlan RK, Jobe FW, et al: The Cybex II evaluation of surgically repaired Achilles tendon ruptures. Am J Sports Med 6(6):369-372, 1978.

12. Saxena A, Cheung S: Surgery for Chronic Achilles Tendinopathy. JAPMA 93(4):283-291, 2003.

13. Kvist M, Jozsa L, Jarvinen MJ, et al: Chronic Achilles paratenonitis in athletes: a histological and histochemical study. Pathology 19:1, 1987.

14. Wilcox DK, Bohay DR, Anderson JG: Treatment of chronic Achilles tendon disorders with flexor hallucis longus tendon transfer/augmentation. Foot Ankle Int 21(12):1004-1010, 2000.

15. Inglis AE, Sculco TP: Surgical repair of ruptures of the tendo Achilles. Clin Orthop Rel Res 156:160-169, 1981.

16. Acevedo, JI; Weber, KS; Eidelman DI: Technique tip: avoiding wound complications after neglected Achilles tendon repair using a tissue expansion technique. Foot \& Ankle Int 28:393-395, 2007.

17. Paavola, M; Orava, S; Leppilahti, J; Kannus, P; Jarvinen, M: Chronic Achilles tendon overuse injury: complications after surgical treatment. An analysis of 432 consecutive patients. Am. J. Sports Med 28:77-82, 2000.

18. Fierro NL, Sallis RE: Achilles tendon rupture. Is casting enough? Postgrad Med 98(3):145-152, 1995.

19. DiStefano VJ, Nixon JE: Achilles tendon rupture: pathogenesis, diagnosis and treatment by a modified pullout wire technique. J Trauma 12:671-677, 1972.

20. Turco VJ, Spinella AJ: Peroneal Brevis Transfer. Foot Ankle 7(4):253-259, 1987.

21. Thompson TC, Doherty JH: Spontaneous rupture of tendon of Achilles: A new clinical diagnostic test. J Trauma 2:126-129, 1962.

22. GW, Griffith TG: Percutaneous repair of acute closed ruptured Achilles tendon: A new technique. Clin Orthop Relat Res 128:247-255, 1977.

23. Couglin MJ ed: Disorders of tendons. In Surgery of the foot and ankle 1149-1277, 2007.

24. Christensen I: Rupture of the Achilles tendon: analysis of 57 cases. Acta Chir. Scand 106:50-60, 1953.

25. Maffulli N. Clinical tests in sports medicine: more on Achilles tendon. Br J Sports Med 30:250, 1996.

26. Wong MWN, Sing VW: Modified flexor hallucis longus transfer for Achilles insertional rupture in elderly patients. Clin Orthop and Rel Res 431:201-206, 2005.

27. Simon SR, Mann RA, Hagy JL, Larsen LJ: The role of the posterior calf muscles in normal gait. J Bone Joint Surg 60A:465-472, 1978.

28. Bosworth DM: Repair of defects in the tendo Achilles. J Bone Joint Surg Am 38(1):111-114, 1956.

29. Gabel S, Manoli A 2nd: Neglected rupture of the Achilles tendon. Foot Ankle Int 15(9):512-517, 1994. 
30. Porter DA, Mannarino FP, Snead D, et al: Primary repair without augmentation for early neglected Achilles tendon ruptures in the recreational athlete. Foot Ankle Int 18(9):557-564, 1997.

31. Miskulin M, Miskulin A, Klobucar H, Kuvalja S: Neglected rupture of the Achilles tendon treated with peroneus brevis transfer: a functional assessment of 5 cases. Journal of Foot Ankle Surg 44(1):49-55, 2005.

32. Wapner KL, Hecht PJ, Mills RH Jr: Reconstruction of neglected Achilles tendon injury. Orthop Clin North Am 26(2):249-263, 1995.

33. Howard CB, Winston I, Bell W, Mackie I, Jenkius DHR: Late repair of the calcaneal tendon with carbon fiber. J Bone Joint Surg 66B:206-209, 1984.

34. Besse JL, Lerat JL, Moyen B, Brunet-Guedj E: Achilles tendon repair using a bone-tendon graft harvested from the knee extensor system: Three cases: JFAS 38(1):70-74, 1999. 35. Barnes MJ, Hardy AE: Delayed reconstruction of the calcaneal tendon. J Bone Joint Surg Br 68(1):121-124, 1986. 36. Nistor L: Surgical and non-surgical treatment of Achilles tendon rupture. A prospective randomized study. J Bone Joint Surg Am 63(3):394-399, 1981.

37. Lead RB, Smith L: Non-surgical treatment of tendo Achilles rupture. J Bone Joint Surg 54A:1398-1407, 1972. 38. Mann RA, Holmes GB Jr, Seale KS, Collins, DN: Chronic rupture of the Achilles tendon: A new technique of repair. J Bone Joint Surg Am 73(2):214-219, 1991.

39. Carden DG, Noble J, Chalmers J, et al: Rupture of the calcaneal tendon. The early and late management. J Bone Joint Surg Br 69(3):416-420, 1987.

40. Kocabey Y, Nyland J, Nawab A, Caborn D:

Reconstruction of Neglected Achilles' tendon defect with peroneus brevis tendon allograft: A case report. Journal Foot Ankle Surg 45(1):42-45, 2006.

41. Helgeland J, Odland P, Hove LM. Achilles tendon rupture. Surgical or non-surgical treatment, Tidsskr Nor Laegeforen 117:1763-1766, 1997.

42. Saltzman CL, Tearse DS: Achilles tendon injuries. J Am Acad Orthop Surg 6:316-325, 1998.

43. Boyden EM, Kitaoka HB, Cahalan TD, An K: Late versus early repair of Achilles tendon rupture. Clin Orthop 317:150-158, 1995.

44. Bugg EI Jr, Boyd BM: Repair of neglected rupture or laceration of the Achilles tendon. Clin Orthop Relat Res 56:73-75, 1968.

45. Hansen S: Trauma to the heel cord. In Jahss M (ed), Disorders of the Foot and Ankle: Medical and Surgical Management, ed. 2. Philadelphia, WB Saunders, 1991, pp 2355-2360.

46. Myerson MS: Achilles tendon ruptures. In AAOS Instructional Course Lectures, 48:219-230, 1999. 47. Wapner KL, Pavlock GS, Hecht PJ, et al: Repair of chonic Achilles tendon rupture with flexor hallucis longus tendon transfer. Foot Ankle 14(8):443-449, 1993.

48. Abraham, E; Pankovich, AM: Neglected rupture of the Achilles tendon. J. Bone Joint Surg 57A:253-255, 1975. 49. Dalton, G; Wapner, K; Hecht, P: Complications of Achilles and posterior tibial tendon surgeries. Clin. Orthop 391:133-139, 2001.
50. Christensen RE: To tilfaelde of subcutan

Achillessenenrupture. Dansk Kir. Selsk. Forh 75:39, 1931. 51. Jessing P, Hansen E: Surgical treatment of 102 tendo Achilles ruptures - suture or tenontoplasty? Acta Chir Scand 141:370-377, 1975.

52. Dalton G: Achilles tendon rupture. Foot Ankle Clin 1:225-236, 1996.

53. Maffulli N, Leadbetter WB: Free Gracilis tendon graft in neglected tears of the Achilles tendon. Clin J Sport Med 15(2):56-61, 2005.

54. Ralston E, Schmidt E: Repair of ruptured Achilles tendon. J. Trauma 11:15-21, 1971.

55. White RK, Kraynick BM: Surgical uses of the peroneus brevis tendon. Surg Gynecol Obstet 108(1):117-121, 1959.

56. Teuffer AP: Traumatic rupture of the Achilles tendon. Orthop Clin N Am 5:89-93, 1978.

57. Clarke HD, Kitaoka HB, Ehman RL: Peroneal tendon injuries. Foot Ankle Int 19:280-288, 1998.

58. Den Hartog BD: Flexor hallucis longus transfer for chronic Achilles tendinosis. Foot Ankle Int 24(3):233-237, 2003.

59. Tashjian RZ, Hur J, Sullivan RF, Campbell JT, DiGiovanni CW: Flexor hallucis longus transfer for repair of chronic Achilles tendinopathy. Foot Ankle Int 24(9):673676, 2003.

60. Pearsall AW, Bryant GK: Technique tip: A new technique for augmentation of repair of chronic Achilles tendon rupture. Foot Ankle Int 27(2):146-147, 2006. 61. Carr AJ, Norris SH: The bood supply of the calcaneal tendon. J Bone Joint Surg 71B:100-101, 1989.

62. Martin RL, Manning CM, Carcia CR, Conti SF: An outcome study of chronic Achilles tendinosis after excision of the Achilles tendon and flexor hallucis longus tendon transfer. Foot Ankle Int 26(9):691-697, 2005.

63. Monroe MT, Dixon DJ, Beals TC et al: Plantarfelxion torque following reconstruction of Achilles tendinosis or rupture with flexor hallucis longus augmentation. Foot Ankle Int 21:324-329, 2000.

64. Coull R, Flavin R, Stephens MM: Flexor hallucis longus tendon transfer: Evaluation of postoperative morbidity. Foot Ankle Int 24(12):931-934, 2003.

65. Lieberman JR, Lozman J, Czajka J, Dougherty J: Repair of Achilles tendon rupture with Dacron vascular graft. Clin. Orthop 243:204-208, 1988.

66. Parsons JR, Weiss AB, Schenk RS, et al: Long-term follow-up of Achilles tendon repair with an absorbable polymer carbon fiber composite. Foot Ankle 9(4):179-184, 1989.

67. Schedl R, Fasol P: Achilles tendon repair with the plantaris tendon compared with repair using polyglycol threads. J Trauma 19:189-194, 1979.

68. Ozaki J, Fujiki J, Sugimoto K, et al: Reconstruction of the neglected Achilles tendon rupture with Marlex mesh. Clin Orthop Relat Res (238):204-208, 1989.

69. Kissel CG, Blacklidge DK, Crowley DL: Repair of neglected Achilles tendon ruptures procedure and functional results. J Foot Ankle Surg 33:46-52, 1994 
70. Nellas ZJ, Loder BG, Wertheimer S: Reconstruction of an Achilles tendon defect using Achilles tendon allograft. J Foot Ankle Surg 35:144-148, 1996.

71. Takao M, Ochi M, Naito K, Uchio Y, Matsusaki M, Oae K: Repair of neglected Achilles tendon rupture using gastrocnemius fascial flaps. Arch Orthop Trauma Surg 123:471-474, 2003.

72. Amis AA, Campbell JR, Kempson SA, Miller JH: Comparison of the structure of neotendons induced by implantation of carbon or polyester fiber. J Bone Joint Surg 66B:131-139, 1984.

73. Poehling GG, Curl WW, Lee CA, Ginn TA, Rushing JT, Naughton MJ, Holden MB, Martin DF, Smith BP: Analysis of Outcomes of Anterior Cruciate Ligament Repair with 5Year Follow-Up: Allograft versus Autograft. Arthroscopy 21(7):774-85, 2005.

74. Nellas ZJ, Lorder BG, Wertheimer SJ: Reconstruction of an Achilles tendon defect utilizing an Achilles tendon allograft. J Foot Ankle Surg 35:144-48, 1996.

75. Yuen JC, Nicholas R: Reconstruction of a total Achilles tendon and soft-tissue defect utilizing an Achilles allograft combined with a rectus muscle free flap. J Plast Reconstr Surg 107:1807-1811, 2000.

76. Lepow GM, Green JB: Reconstruction of a Neglected Achilles Tendon Rupture with an Achilles Tendon Allograft: A Case Report 45(5):351-55, 2006.

77. Mahirogullari M, Ferguson CM, Whitlock PW, Stabile KJ, Poehling GG: Freeze-Dried Allografts for Anterior Cruciate Ligament Reconstruction 26:625-37, 2007.

78. Yasuda T, Kinoshita M, Okuda R: Reconstruction of Chronic Achilles Tendon Rupture with the use of interposed tissue between the stumps. American Journal of Sports Medicine 35(4):582-588, 2007. 